\title{
A political prescription is needed to treat obesity
}

\author{
John Fletcher MB BChir MPH, Kirsten Patrick MBBCh DA
}

$\mathrm{L}$ ast year, World Health Organization (WHO) member states declared a target to stop the rise in obesity by 2025 as part of their commitment to act on noncommunicable diseases. ${ }^{1}$ A report from the Global Burden of Disease Study on global, regional and national trends in overweight and obesity from 1980 to 2013 has shown that obesity is still increasing worldwide, including in Canada, particularly among young people. ${ }^{2}$ The WHO is convening the Commission on Ending Childhood Obesity, which has yet to start a process that will lead to policy recommendations. Stopping the rise of obesity and ending childhood obesity are laudable goals, but they cannot be achieved without a new approach. Governments must recognize that individual-level interventions, nutritional advice and activity guidance are not working. Obesity will only be curbed by population-level measures supported by legislation.

Treating obesity does not work well; preventing it would be better. The global failure to manage obesity, now considered by the American Medical Association to be a disease, may be considered a failure of the evidence-based medicine approach to treating disease. Evidence on factors associated with obesity or interventions that show modest, short-lived effect are not lacking. We know that most restrictive diets result in only short-term weight loss that frequently reverses and worsens in the long term, but dietary changes that are sustainable as a lifestyle choice may work. Physical activity is not enough to prevent or treat obesity and overweight, unless it is combined with some kind of dietary intervention. Family and community interventions may work somewhat better than interventions aimed at individuals, but their implementation is patchy. Bariatric surgery has good results in the treatment of morbid obesity, but its use is always going to be limited and a last resort. Pharmaceutical agents may work to some extent, but may have nasty adverse effects. We are over-endowed with nutritional guidelines, official and unofficial, and yet, despite all of this evidence, we have failed to make a discernible impact on the problem at the population level.

Why do we continue to rely on broad public health guidance and treatments of dubious effectiveness as the main thrust of our approach to managing obesity? The Public Health Agency of Canada and the Canadian Institute for Health Information, in their joint report on obesity in Canada, categorize approaches to countering obesity as follows: "1) health services and clinical interventions that target individuals; 2 ) community-level interventions that directly influence individual and group behaviours; and 3) public policies that target broad social or environmental determinants." ${ }^{3}$ The report acknowledges that there is unlikely to be a single solution that will reverse the rising prevalence of obesity in Canada and that a multisectoral response may be required. ${ }^{3}$ Individual communities are delivering innovative programs and should be applauded for taking the initiative, but when it comes to public policy, the government is just not doing enough.

Our current approach to obesity relies on the assumption that people have choices, often fail to make the right ones, and should be educated and helped to make better choices. This view is simplistic and clearly absurd, given the continued rise in the prevalence of obesity in countries that have been tackling the problem for decades. Are millions of people really choosing to be overweight? People are not as free to choose as we would like to believe. Neurobiological desires for sweet and high-fat foods gave humans a survival advantage in a world where food was scarce and every calorie counted. Where food is inexpensive and easily available, biological processes related to eating can mirror addiction and will lead to our destruction.

We need to change our approach. We need incentives beyond educational messages. Strategies that include individual interventions, school-based nutrition and activity interventions, incentives for active commuting and changes to the built environment should continue; however, we also need robust ways to restrict portion sizes and reduce the sale of sugar-sweetened beverages and other high-calorie, nutrientpoor food products. Our government needs to consider taxation as a tool to combat the consumption of these addictive foods and beverages, just as it regulates the sale of alcohol and tobacco products for the purposes of population health.

To increase sales, food manufacturers deliberately exploit our appetites, desires and addictions with aggressive marketing and by manipulating foods. This is normal corporate behaviour where the goal is to maximize profits. Government can counteract these tactics through the tried-andtested approaches of taxation and regulation that have been applied with success to reduce smoking rates. It is time to apply this same thinking to the food delivery systems that are making us fat. Our government needs to act to restrict the sale of high-calorie and nutrient-poor food products or reduce the incentive to buy them through increasing their prices via taxation.

See references, www.cmaj.ca/lookup/suppl/doi:10.1503/cmaj.141306/-/DC1

Competing interests: See www.cmaj.ca/site/misc/cmaj_staff.xhtml

Affiliations: John Fletcher is Editor-in-Chief and Kirsten Patrick is Deputy Editor, CMAJ

Correspondence to: $C M A J$ editor, pubs@ @maj.ca

CMAJ 2014. DOI:10.1503/cmaj.141306 